ISSN (Print): 2709-9636 | ISSN (Online): 2709-9644

Volume 2, 2021(Issue III, July to September)

$$
\begin{aligned}
& \text { إغإن }
\end{aligned}
$$

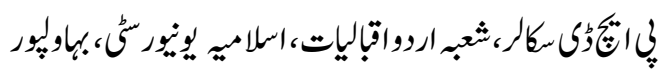

$$
\begin{aligned}
& \text { واكمرلياتت }
\end{aligned}
$$

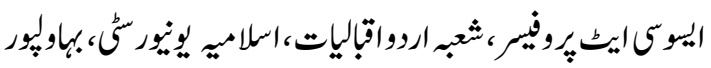

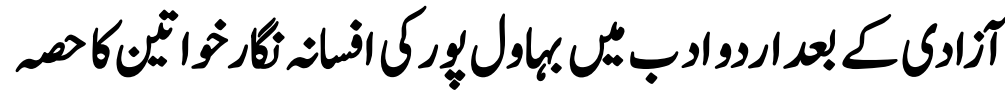

\section{Ejaz Naseem}

Ph.D Scholar, Department of Urdu \& Iqbaliyat, Islamia University, Bahawalpur.

\section{Dr. Liaqat Ali}

Associate Professor, Department of Urdu \& Iqbaliyat, Islamia University, Bahawalpur.

\section{Bahawalpur Fiction Writers share Women's Part in Urdu Post-Independence}

The land of Bahawalpur is an important part of Pakistan. This excellent historical inheritance is situtated in the heart of Pakistan. This territory has its own separate recognition in the light of knowledge and literature. The beginning of Urdu prose in Bahawalpur was begun by Mirza Muhammad Ashraf Gorgani's Shama Shami, Bin Basi Rustam. While Ali Ahmad Riffat, Mahmood Ali Fasoon and Hnayat Tareen explored the literary tradaition by writing their fictions. After the establishment of Pakistan, men and woman partricipated actively in the Urdu fiction. Besides the men writers of fiction, there is a large list of women writers, who in comparison with men writers, wrote while taking quality and quantity into account. They not only discussed the problems of women but also written fiction while taking into account the techniques of art and artifice. In this research article after the independence of Pakistan. The women writers of fiction of Bahawalpur will be analyzed.

Keywords: Fiction, Woman short story, Bahawal Pur, Excellent Historical Inheritance, The Literary Tradatian, After independence. 


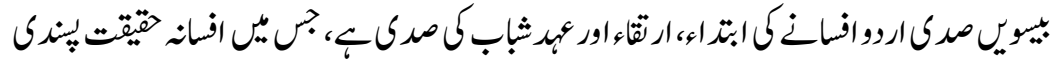

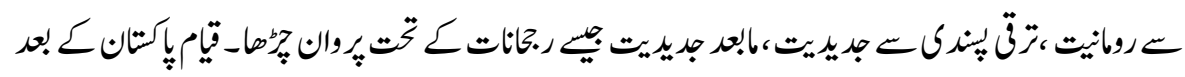

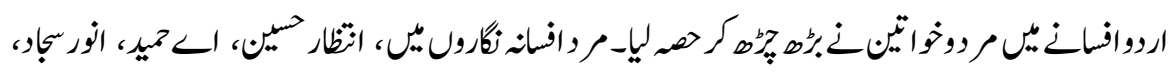

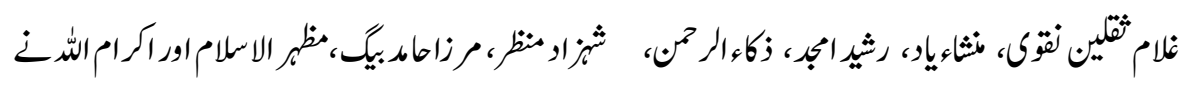

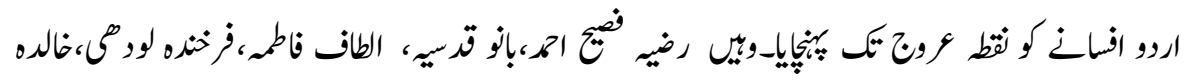

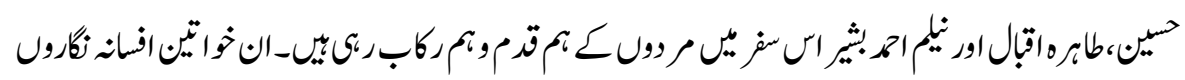

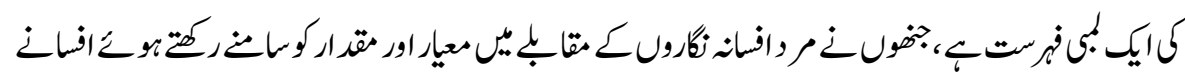

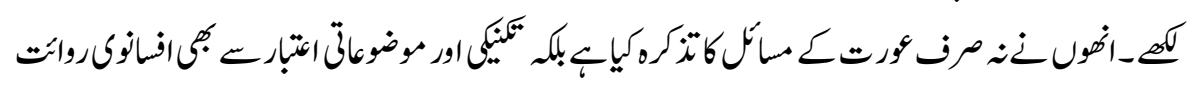
كو آع بر.

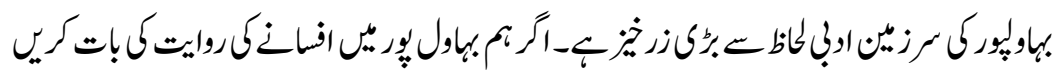

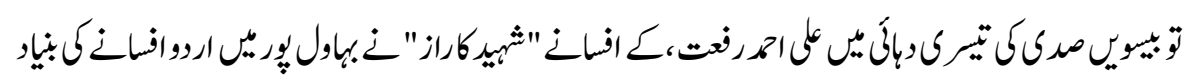

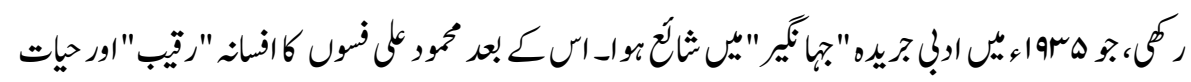

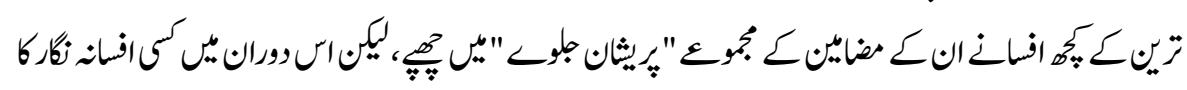

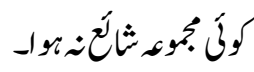

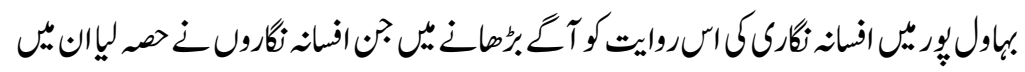

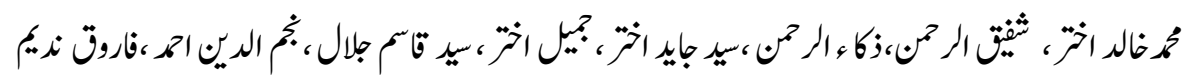

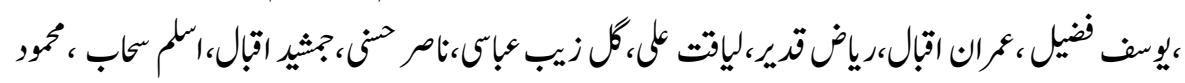

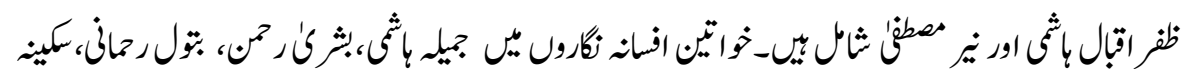

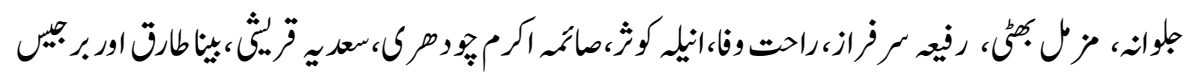

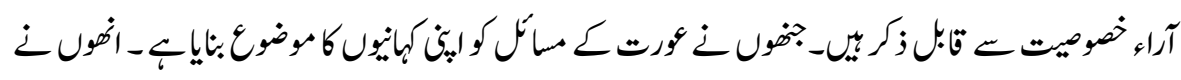

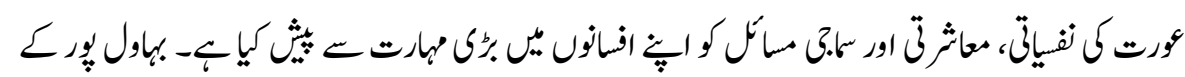

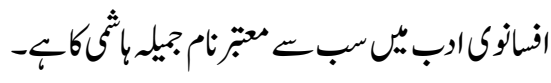




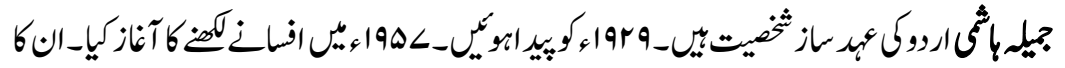

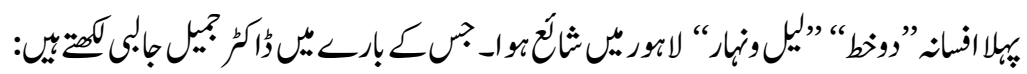

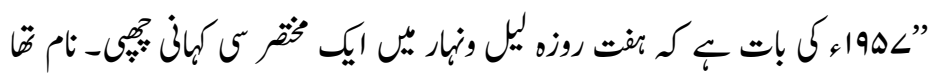

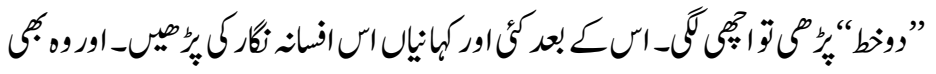

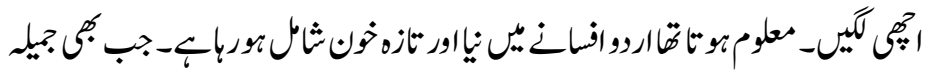

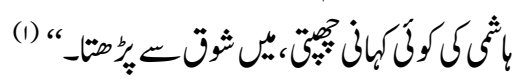

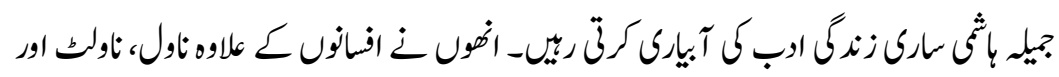

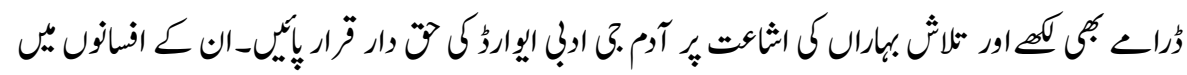

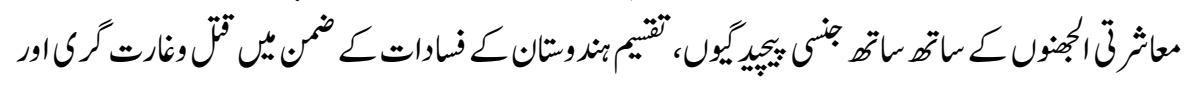

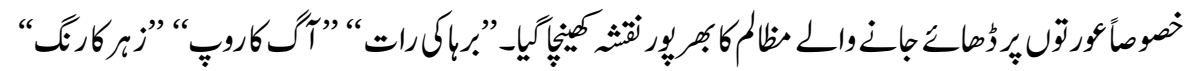

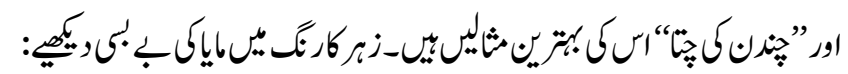

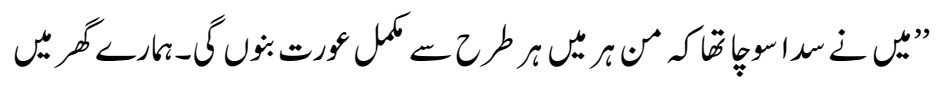

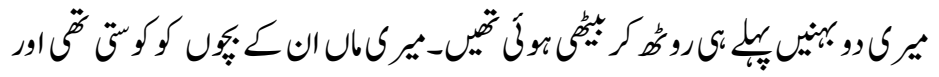

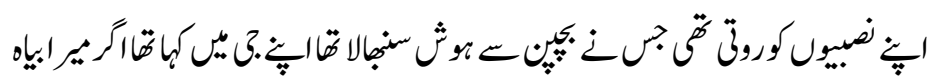

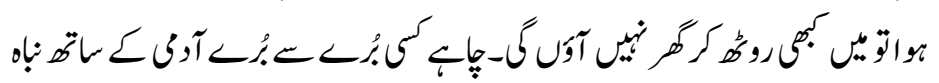

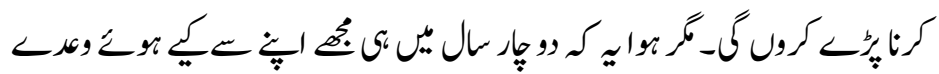

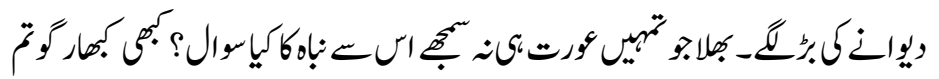

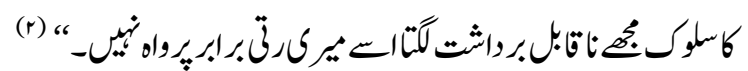

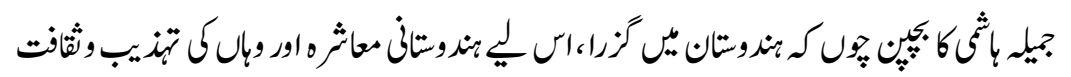

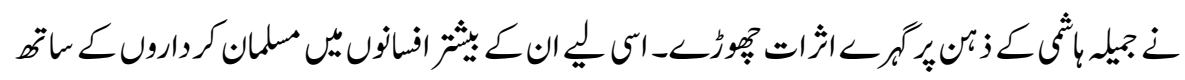

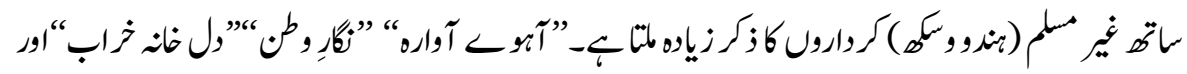

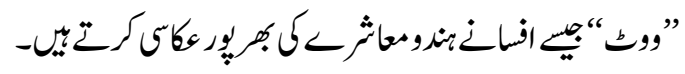


ISSN (Print): 2709-9636 | ISSN (Online): 2709-9644

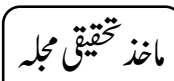

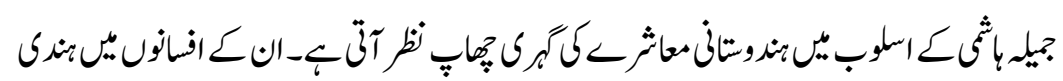

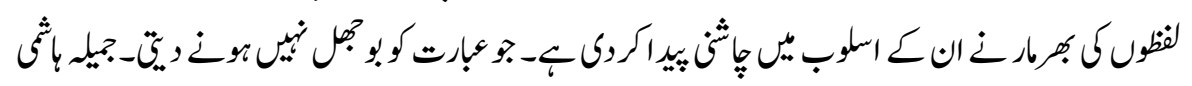

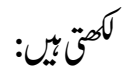

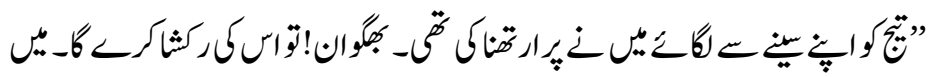

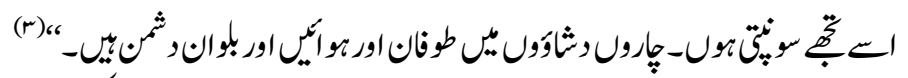

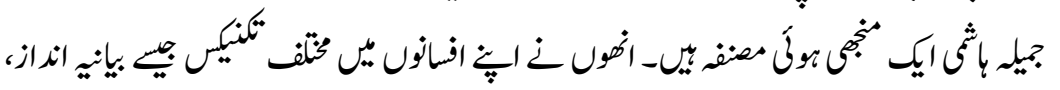

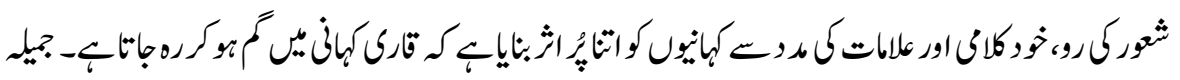

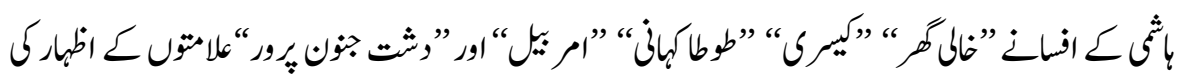

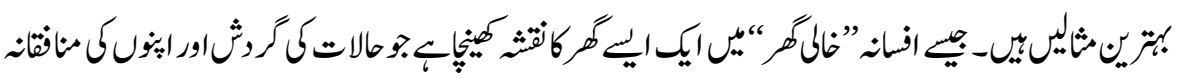

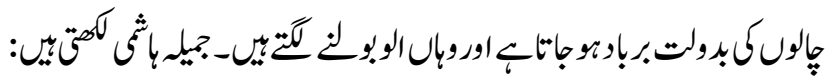

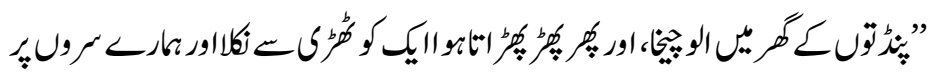

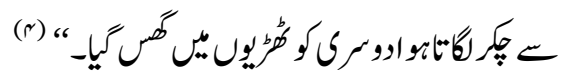

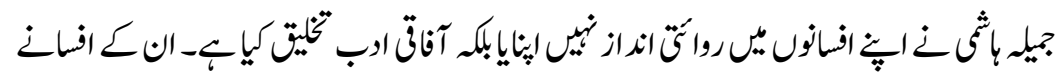

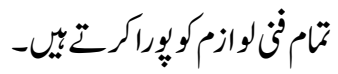

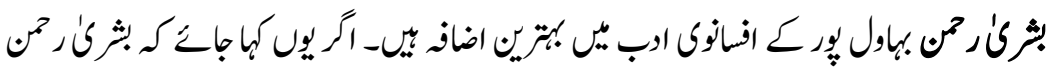

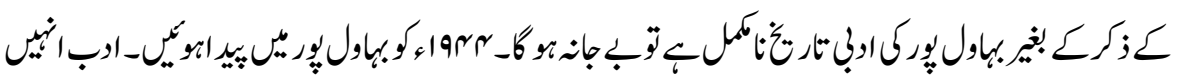

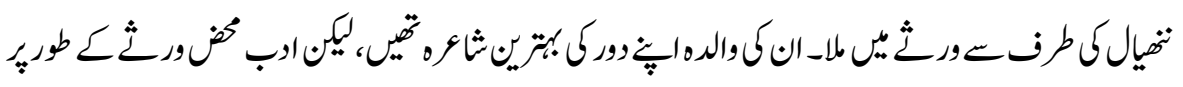

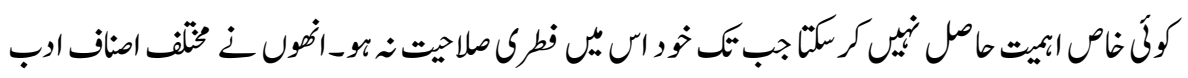

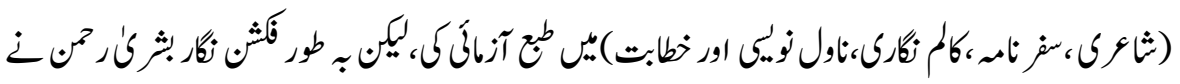

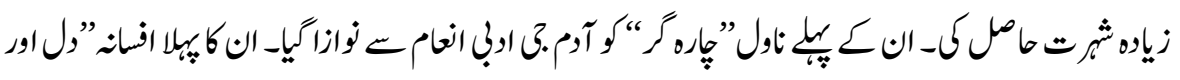

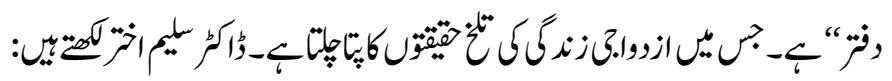

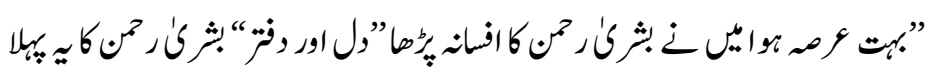

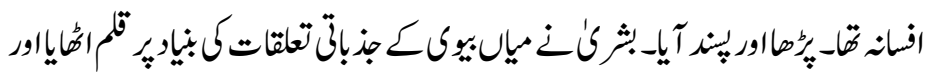

11. 


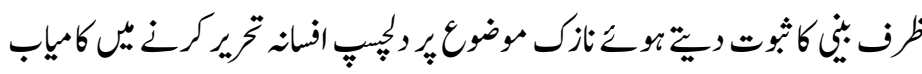

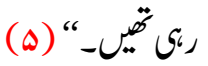

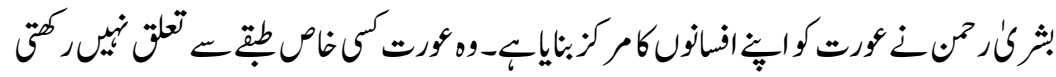

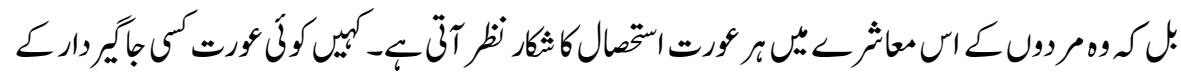

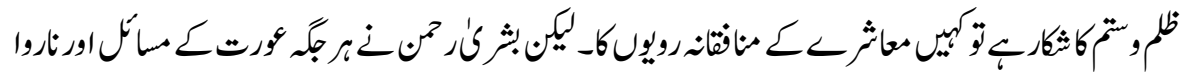

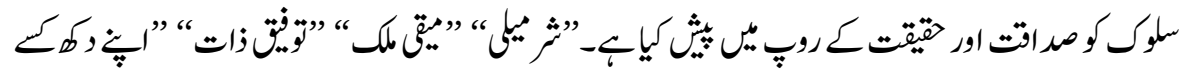

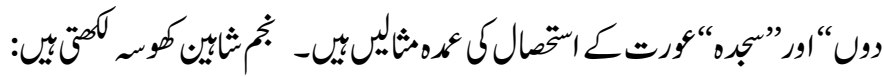

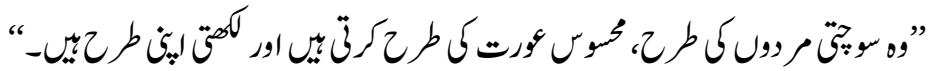

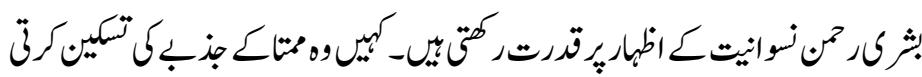

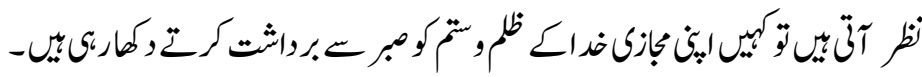

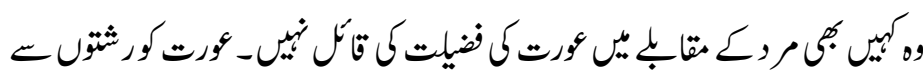

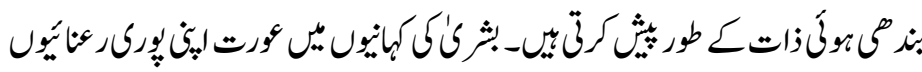

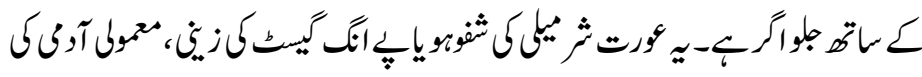

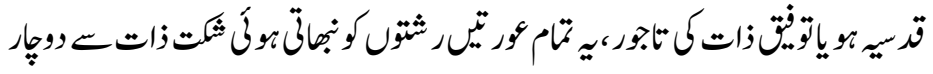

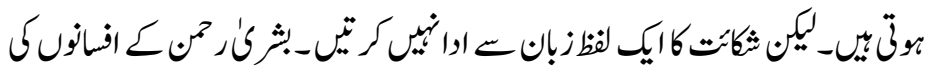

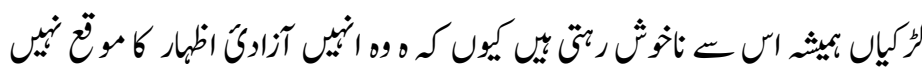

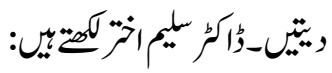

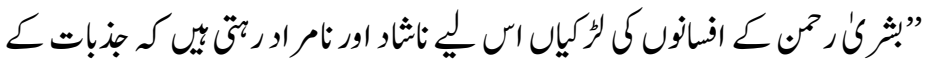

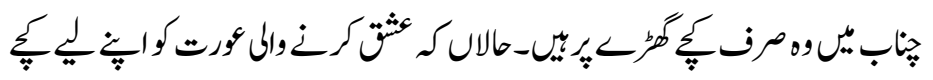

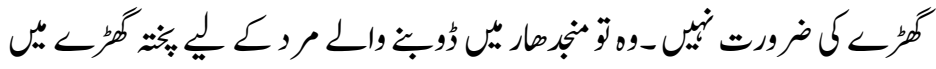




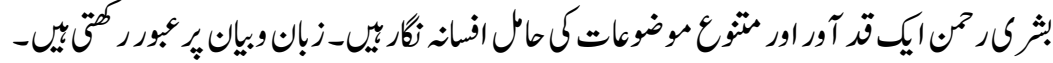

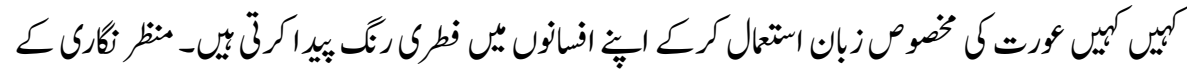

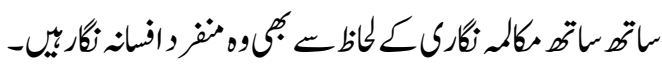

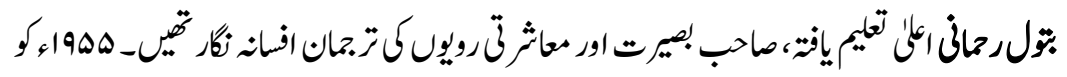

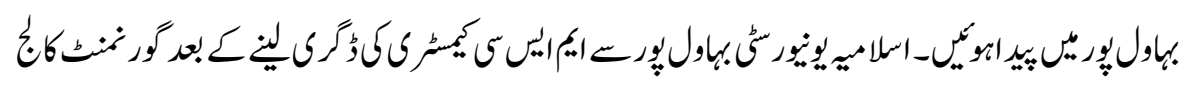

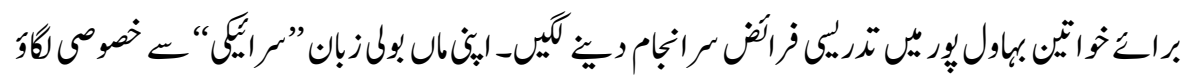

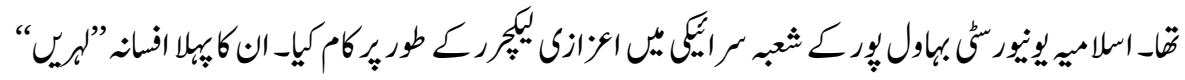

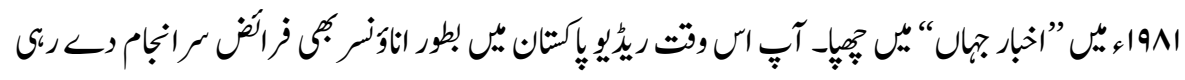

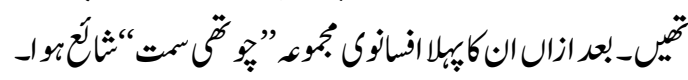

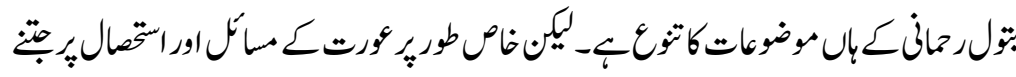

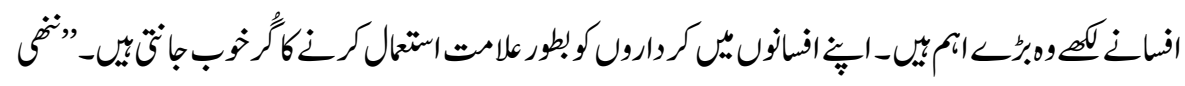

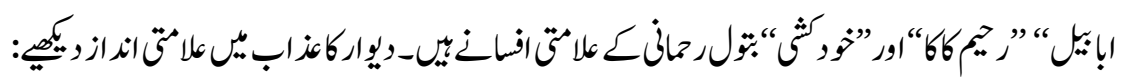

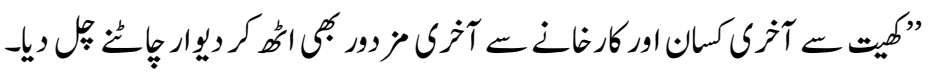

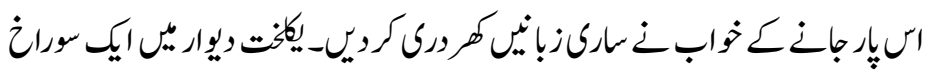

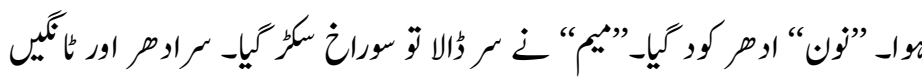

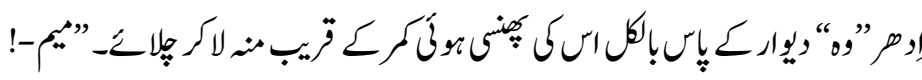

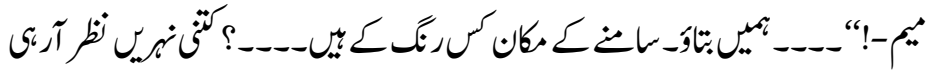

(1) “ “-

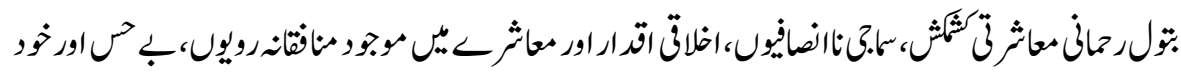

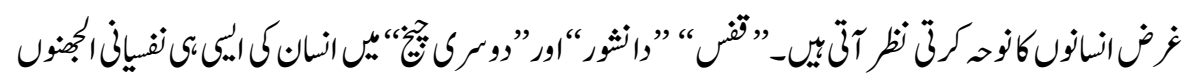


ISSN (Print): 2709-9636 | ISSN (Online): 2709-9644

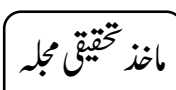

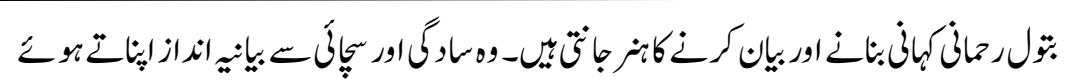

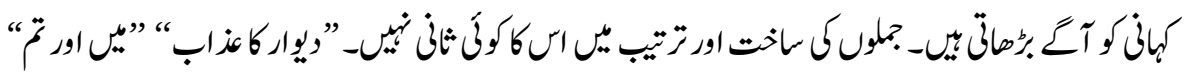

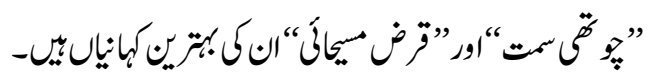

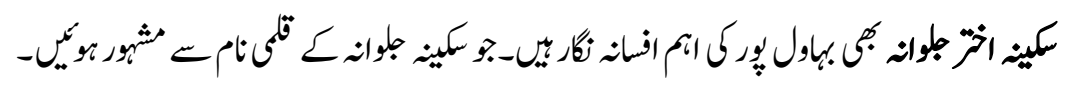

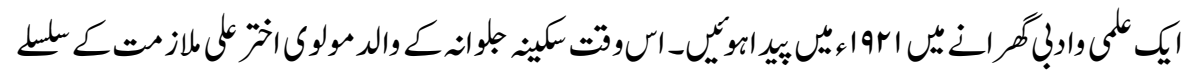

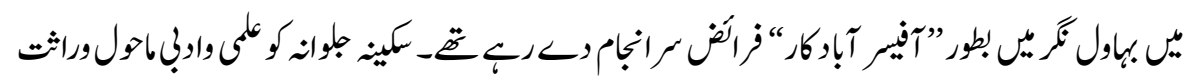

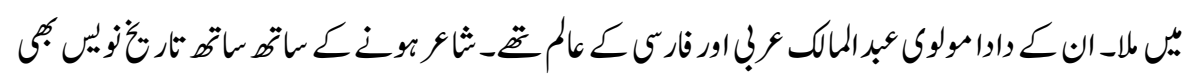

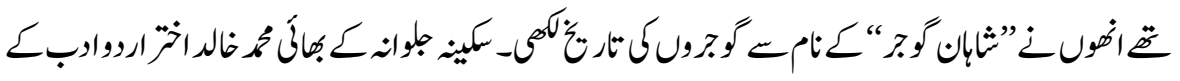

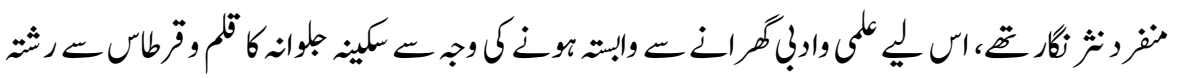

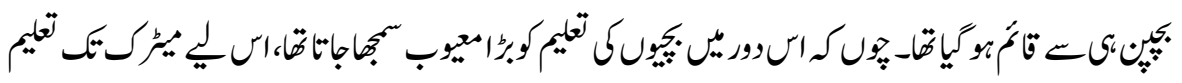

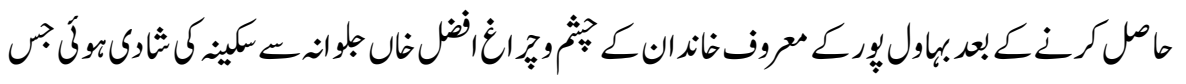

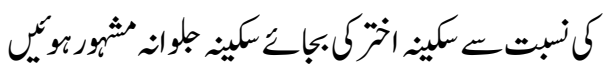

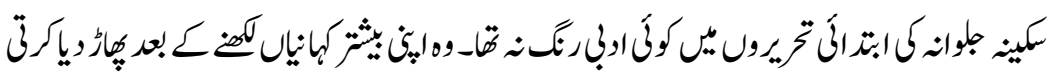

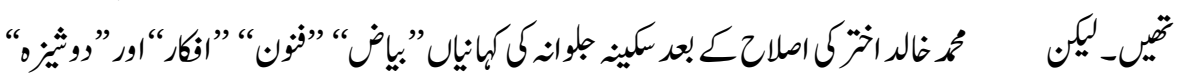

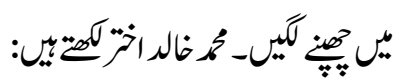

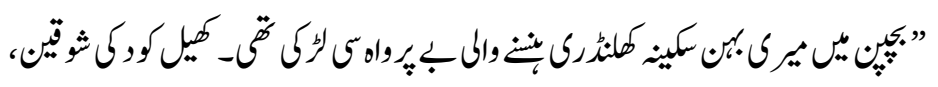

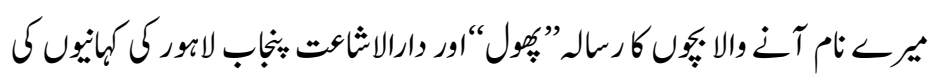

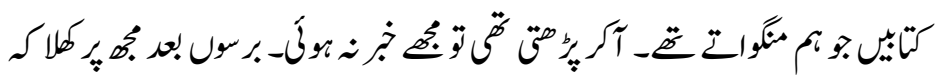

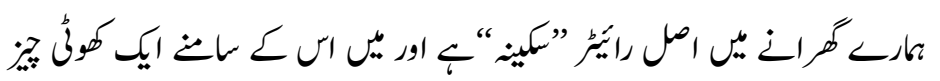

(9)،

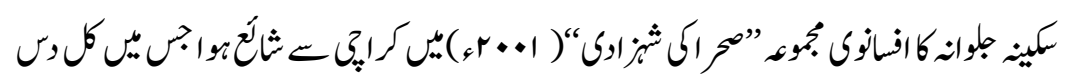

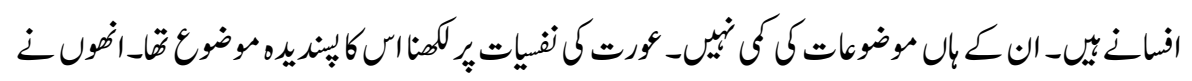

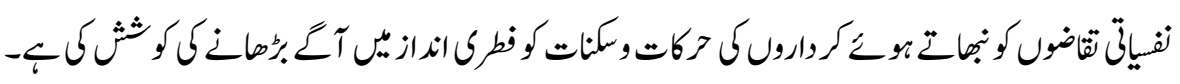

$1 \mathrm{NM}$ 


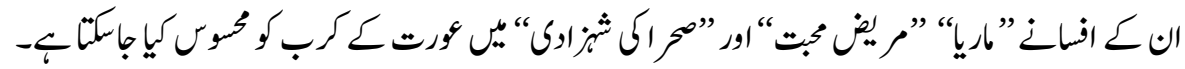

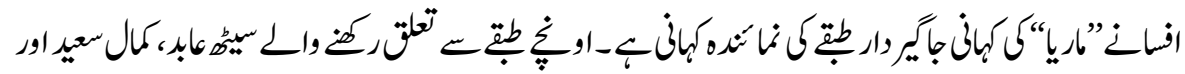

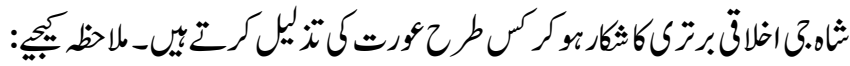

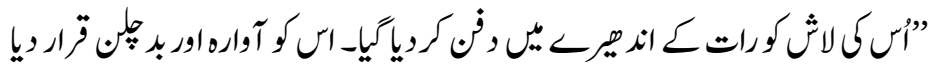

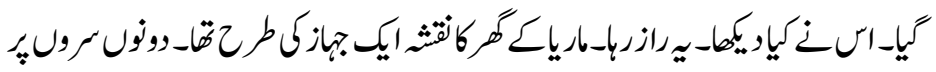

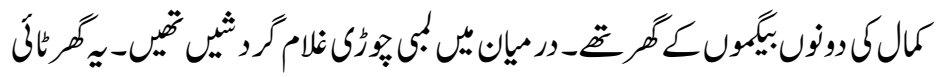

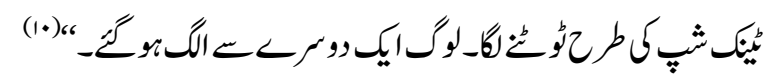

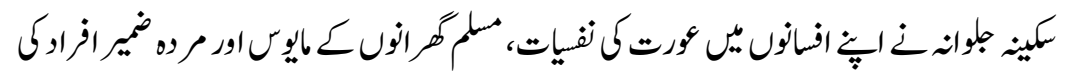

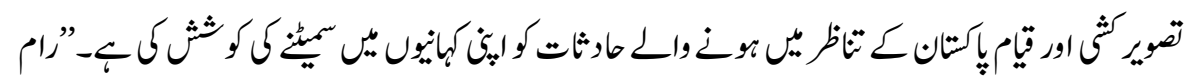

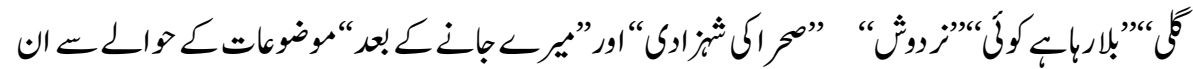

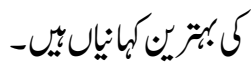

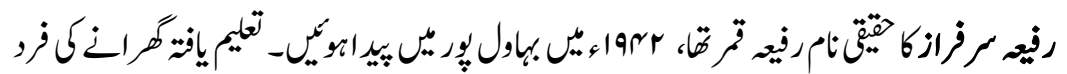

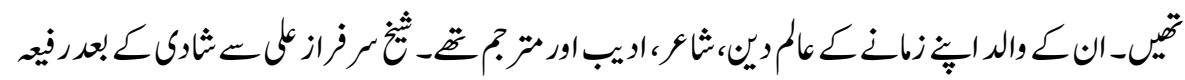

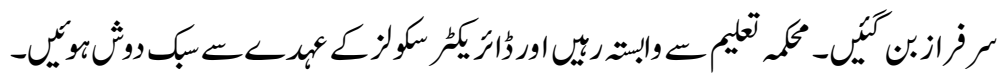

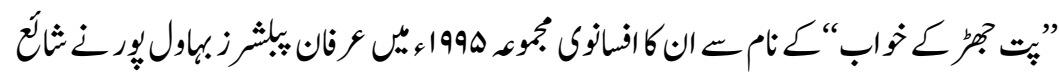

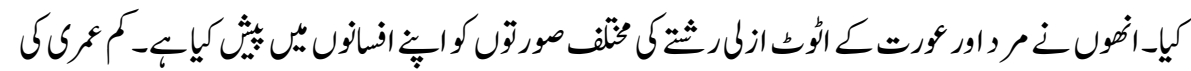

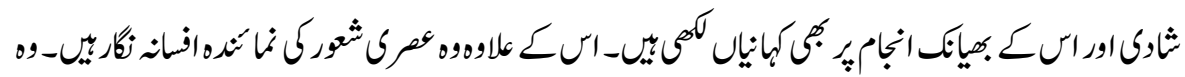

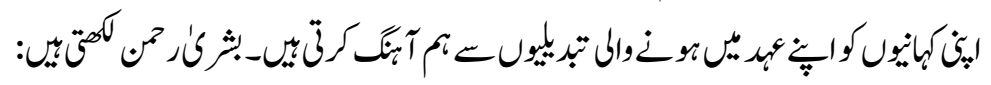

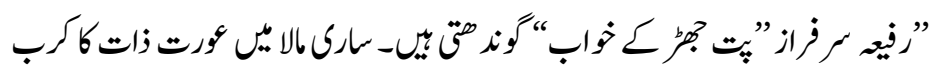

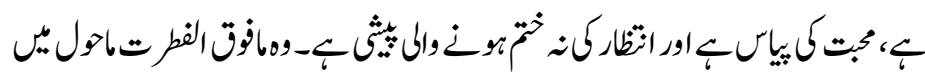

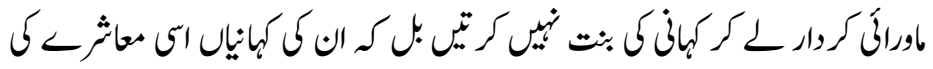

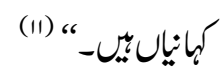


ISSN (Print): 2709-9636 | ISSN (Online): 2709-9644

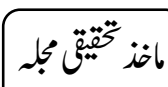

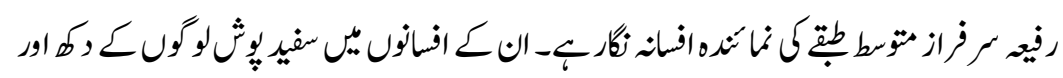

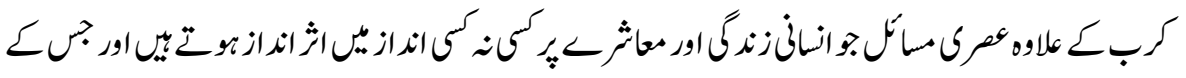

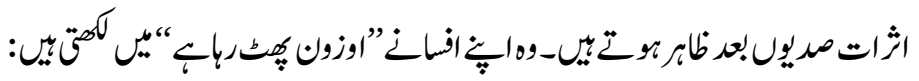

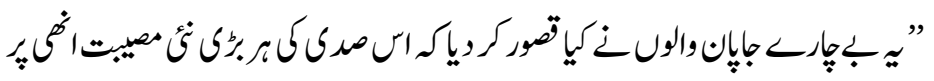

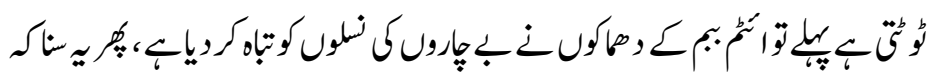

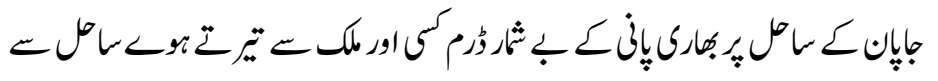

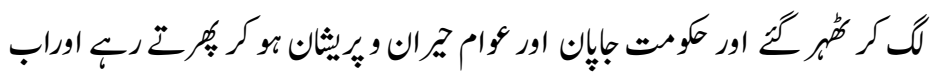

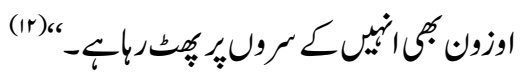

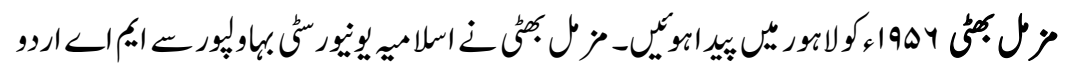

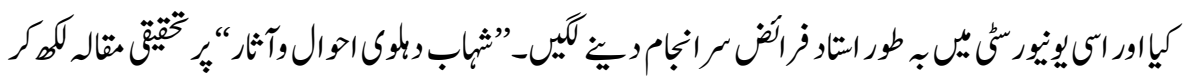

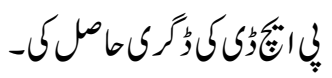

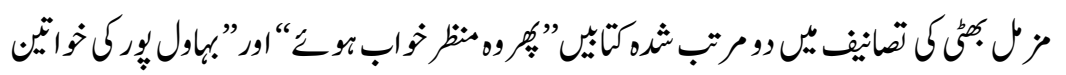

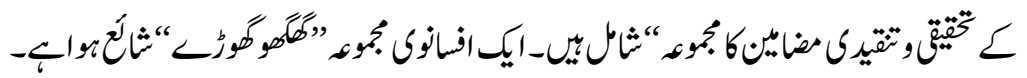

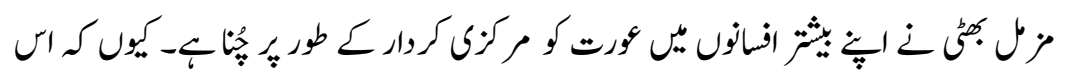

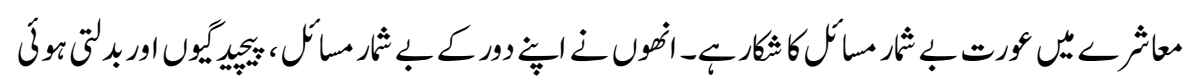

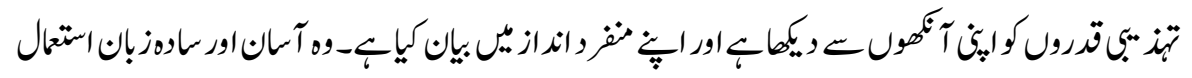

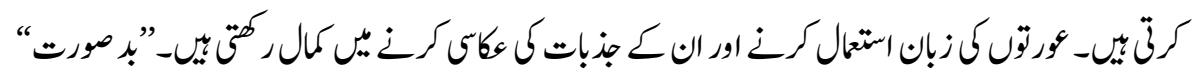

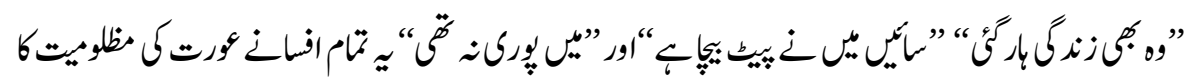

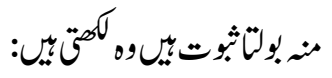

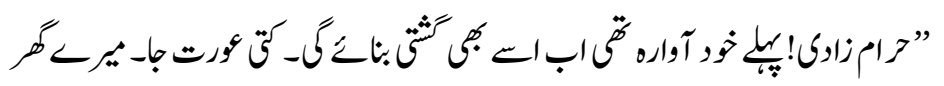

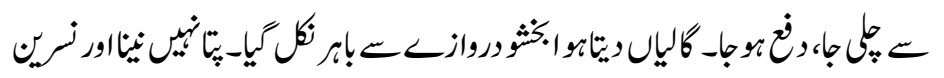

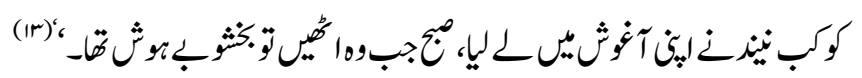

$1 \wedge \omega$ 


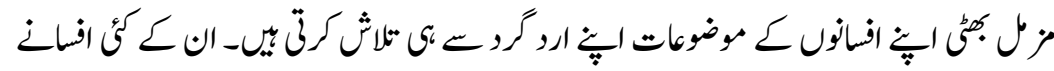

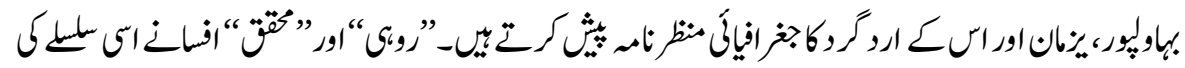

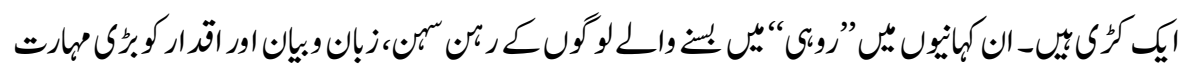

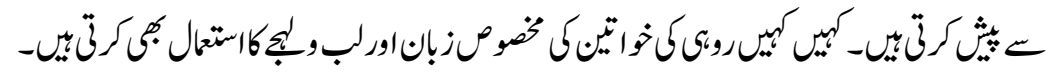

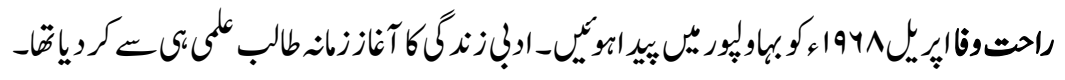

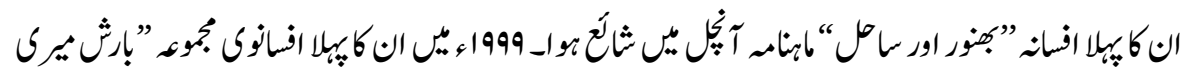

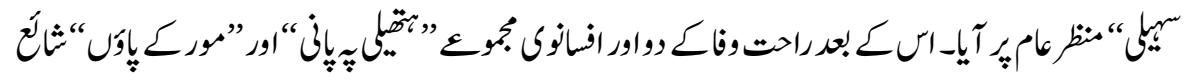

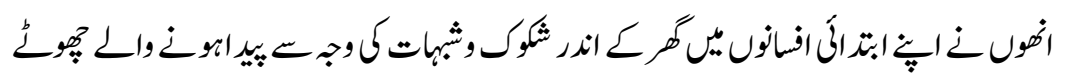

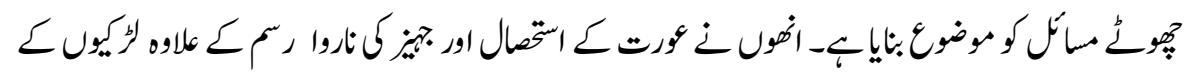

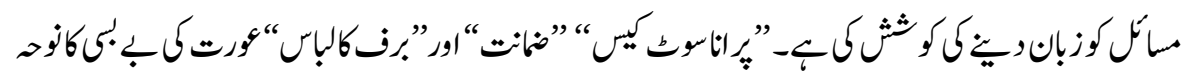

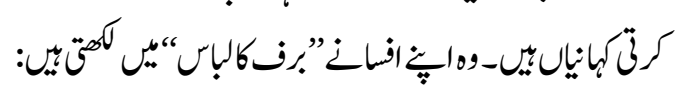

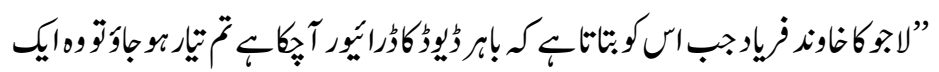

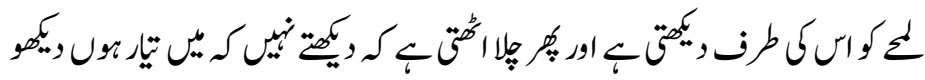

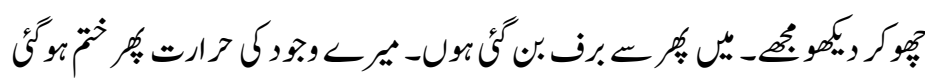

$\left(1 r^{\prime}\right) " C$

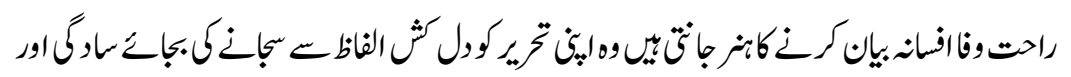

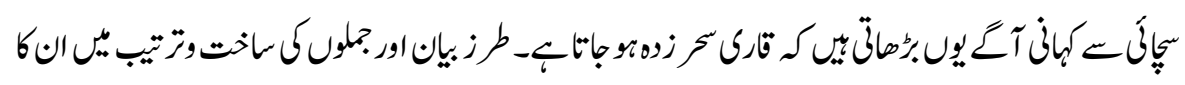

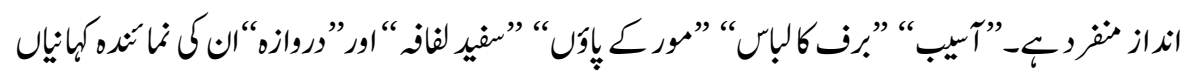

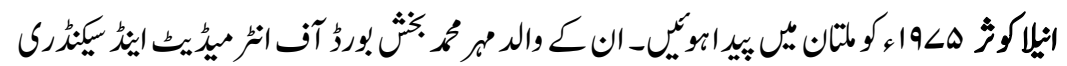

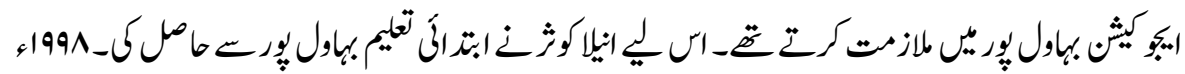

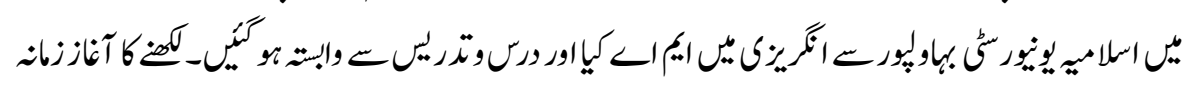


ISSN (Print): 2709-9636 | ISSN (Online): 2709-9644

Volume 2, 2021(Issue III, July to September)

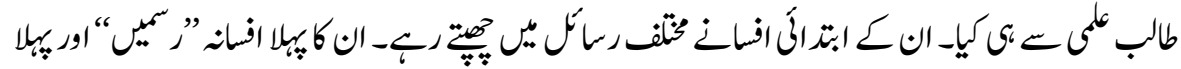

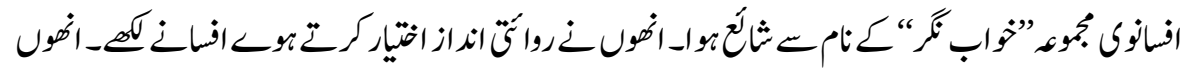

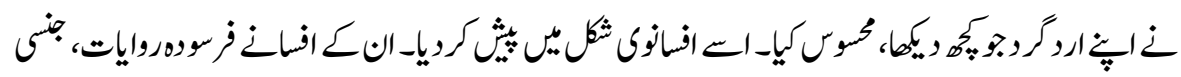

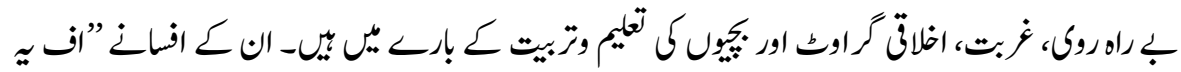

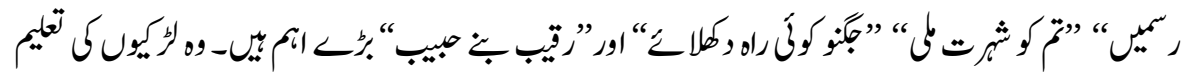

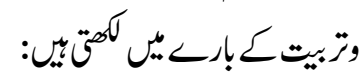

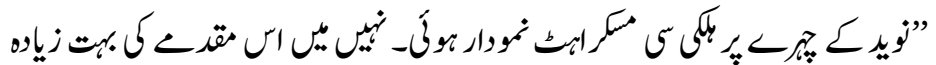

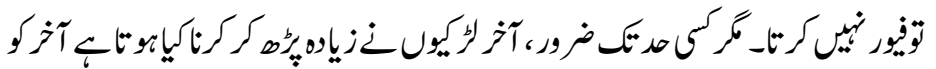

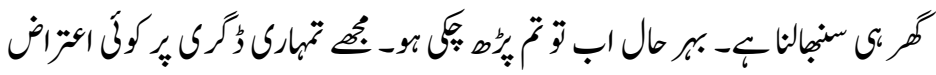

(10) ،

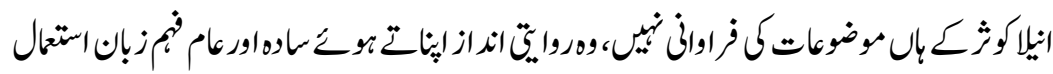

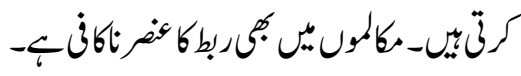

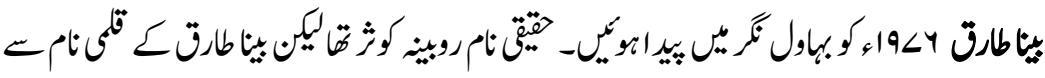

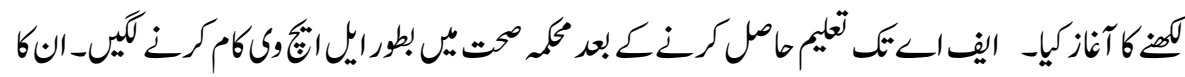

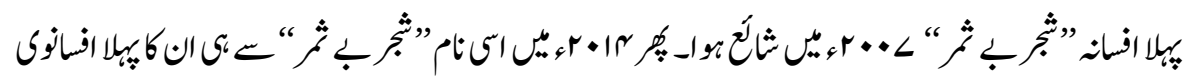

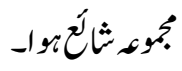

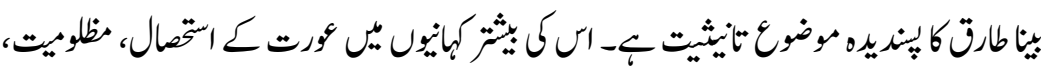

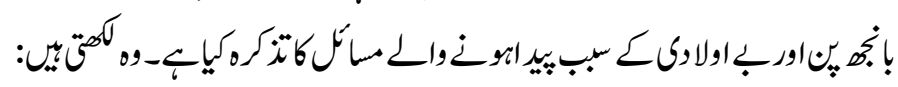

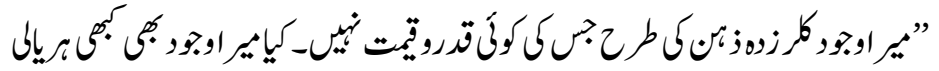

$$
\text { (14)" }
$$

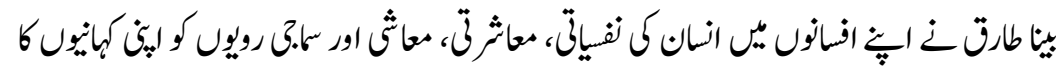

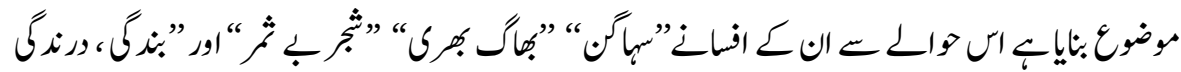

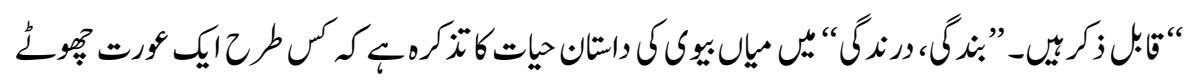


ISSN (Print): 2709-9636 | ISSN (Online): 2709-9644

Volume 2, 2021(Issue III, July to September)

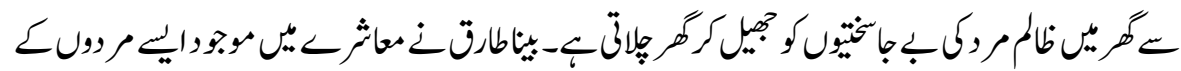

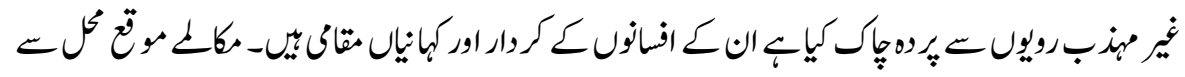

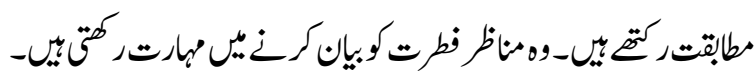

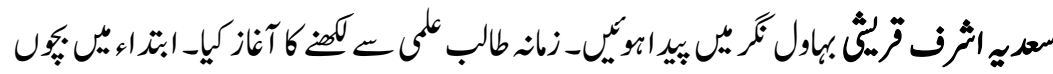

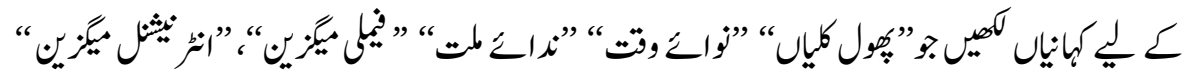

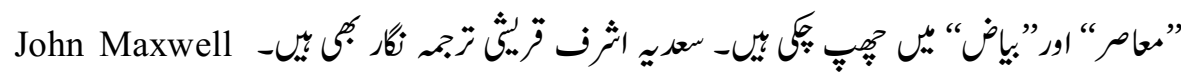

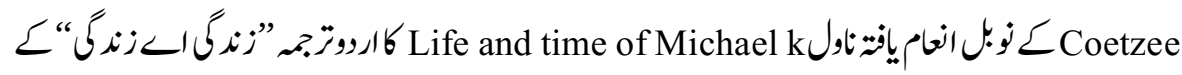

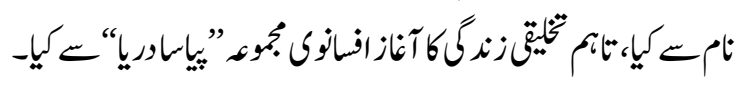

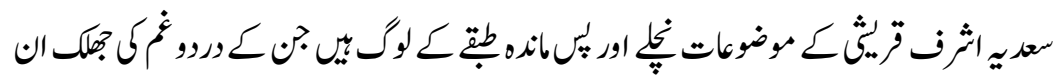

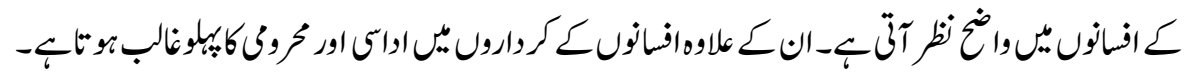

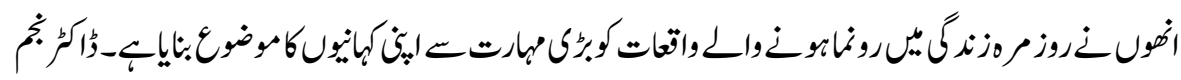

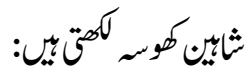

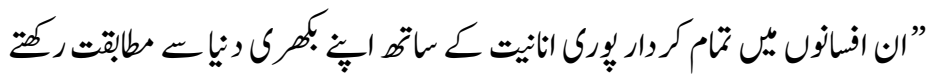

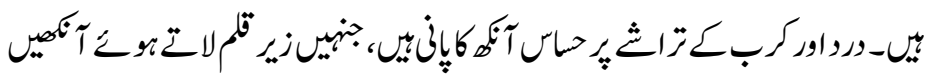

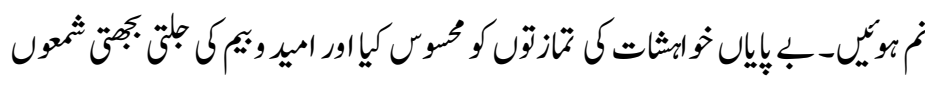

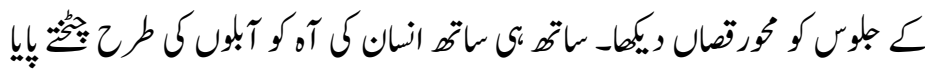
(17)،

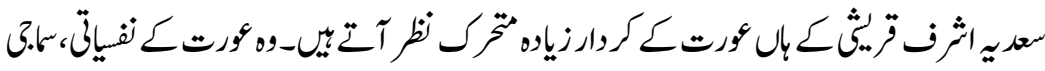

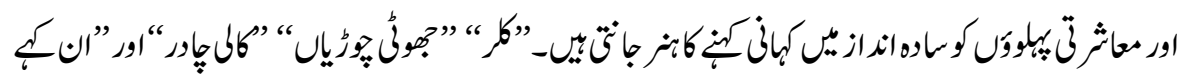

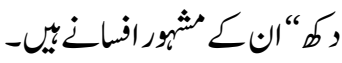

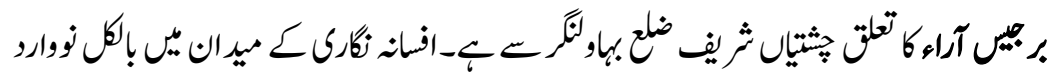

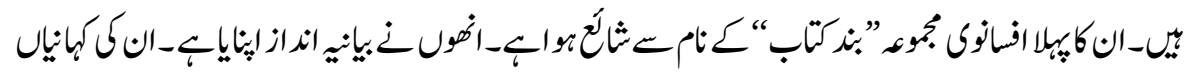

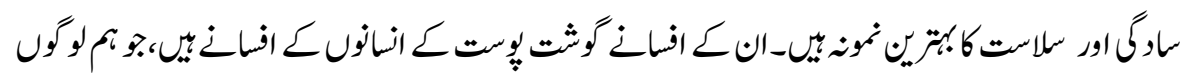


ISSN (Print): 2709-9636 | ISSN (Online): 2709-9644

Volume 2, 2021(Issue III, July to September)

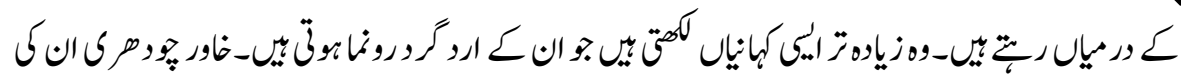

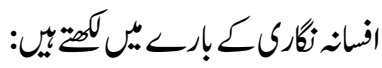

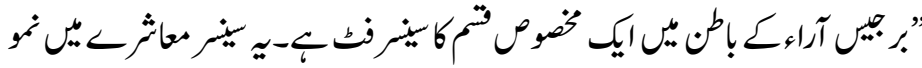

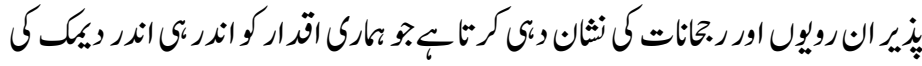

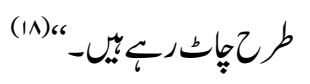

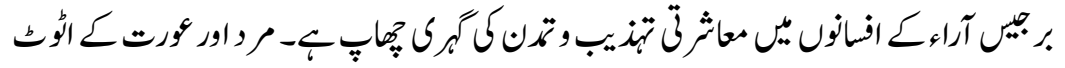

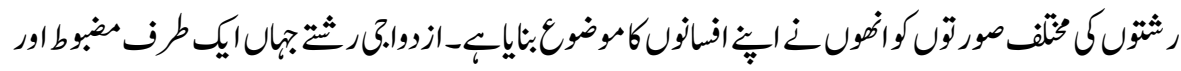

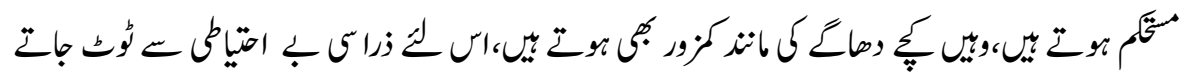

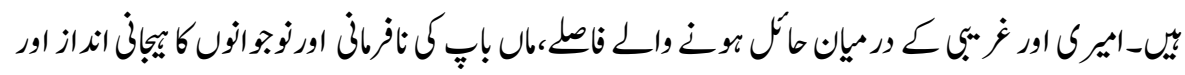

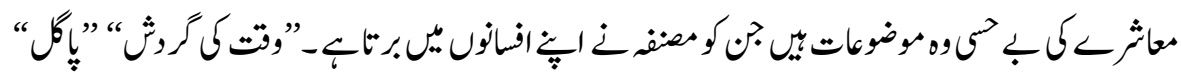

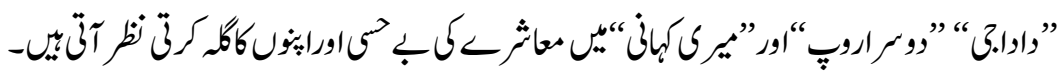

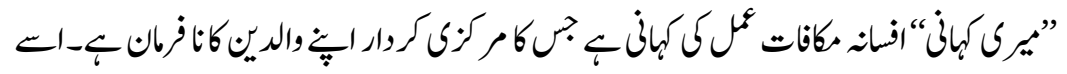

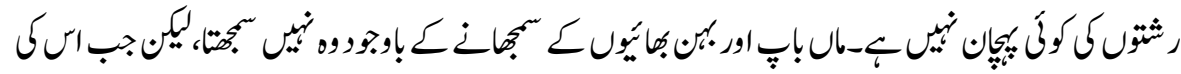

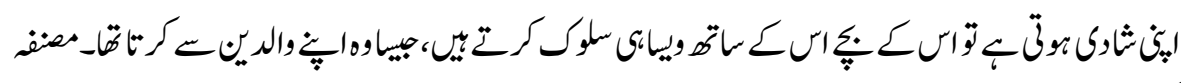

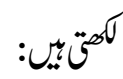

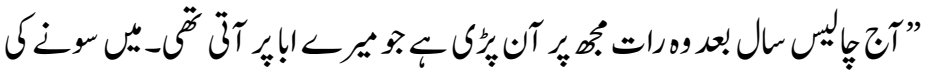

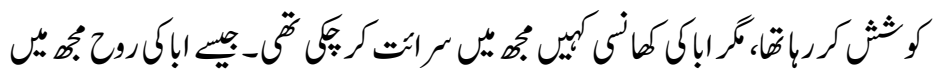

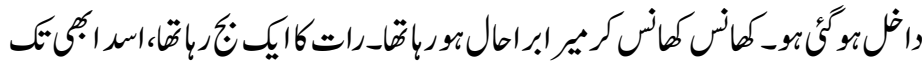

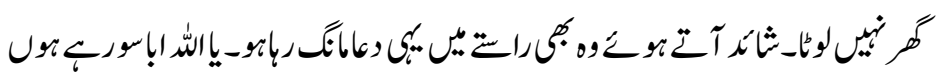

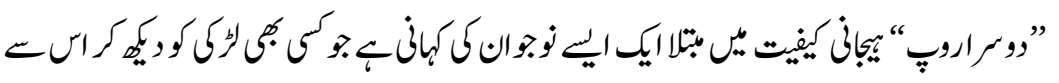

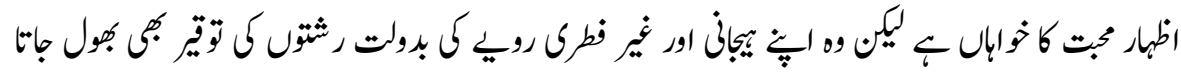

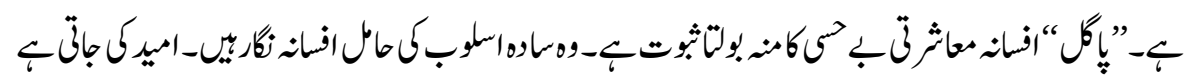


ISSN (Print): 2709-9636 | ISSN (Online): 2709-9644

Volume 2, 2021(Issue III, July to September)

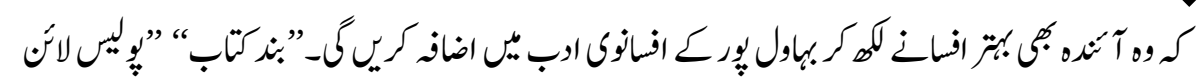

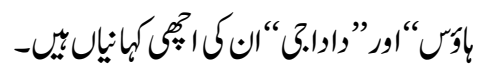

\section{والرجات}

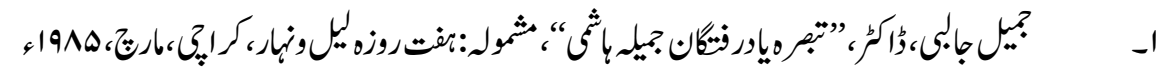

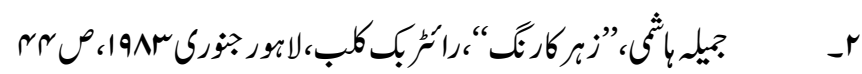

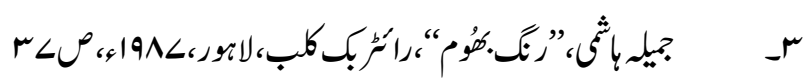

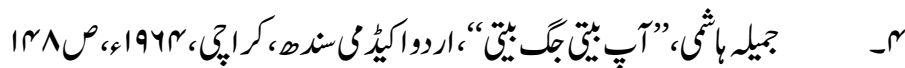

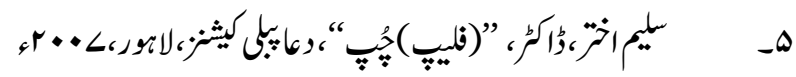

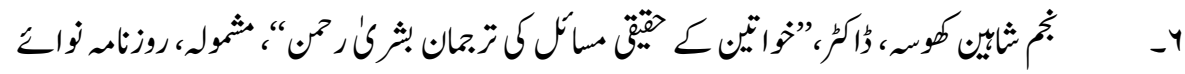

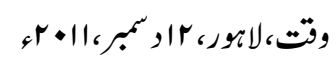

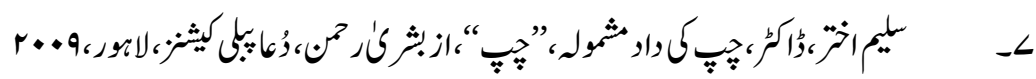

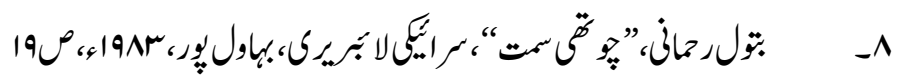

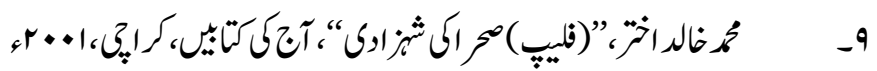

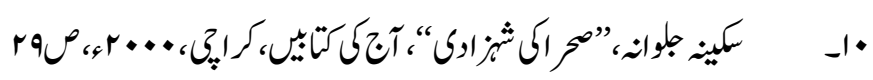

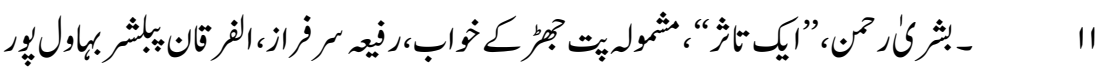

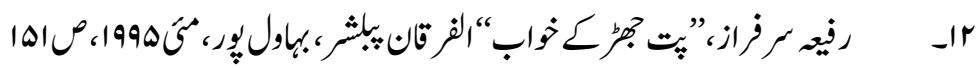

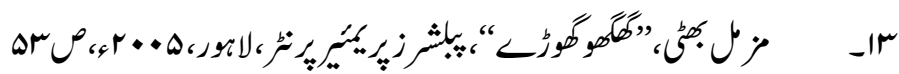

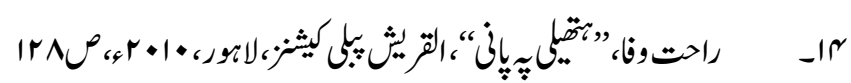

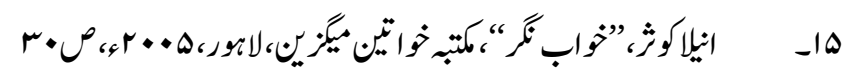

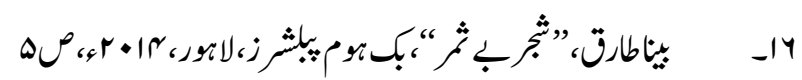

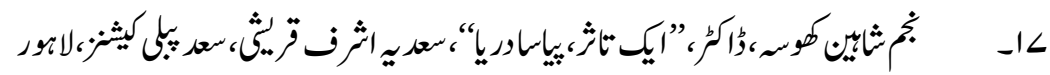

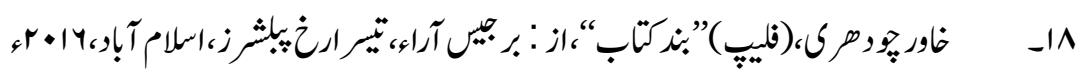

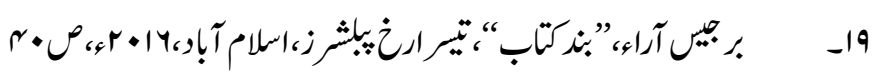

